\title{
Violencia y terror sobre los cuerpos
}

\author{
Manuel Durán \\ Doctor (c) Universidad de Santiago de Chile \\ lamuerteyladoncella@hotmail.com
}

\begin{abstract}
“Nunca olvidaré el bárbaro asesinato de mi amor ante mis ojos, ante nuestros ojos, porque había cientos de testigos..."
\end{abstract}

Pierre Seel. Moi, Pierre Seel, Déporté Homosexuel.

Las políticas del terror se encuentran presentes en todos los ámbitos de nuestra sociedad: político, institucional y educacional. Asumiendo la violencia como algo "natural". Desde los márgenes ocultos de los ataques homofóbicos, hasta el ejercicio institucional de la justicia en casos emblemáticos como el de la jueza Karen Atala.

Estos actos evocan en mi mente las imágenes terribles de los campos de exterminio y las políticas de segregación. En ghetos, barracas, e incluso en la hermoseada y vigilada ciudad neoliberal.

Cuantas veces la muerte y la violencia cobraron justificación en la ciencia, la salud, la moral y la conquista, arrojando feroces perros contra los cuerpos abyectos, destruyendo entre sus fauces toda huella que nos recordara la marca de lo anómalo, de lo subversivo.

Los sujetos, en consecuencia, somos concebidos como dispositivos de producción y violencia, ligado a instituciones como el matrimonio, la familia y la ciudadanía. De esta forma el cuerpo devino en herramienta y fusil del Estado moderno, estableciendo una ética del terror sobre el cuerpo.

Ante esta maquinaria disciplinadora los sujetos díscolos han generado diversas formas de escape. Resignificando los signos tridentinos en torno a la sexualidad, en espacios fronterizos como las 
chinganas, el monte, la noche, incluso en los claustros coloniales. Dichas prácticas y espacios se niegan a la normalización, a educarse, a higienizarse y evangelizar.

Este sistema de coerción nos ha marcado con el signo de la injuria. Desde que éramos disciplinados estudiantes soportando las agresiones del resto de nuestros compañeros, (los llamados policías del género), dispuestos a castigar con severidad cualquier manera que se escape a la norma, hasta profesionales productivos y saneados.

Es por ello que muchos ocultamos nuestra diferencia, creyendo estar seguros al encubrir nuestra identidad, fingiendo afectos, ajustándonos y disimulando nuestro andar.

En este ámbito el evidenciar la diferencia se constituye en un proyecto político. Rompiendo con la ilusión del heterosexismo universal. Así lo dice el escritor Pedro Lemebel en su famoso manifiesto por la diferencia, donde denuncia justamente las desigualdades que se originan al margen de estos proyectos ideológicos:

....No necesito disfraz

Aquí está mi cara

Hablo por mi diferencia

Defiendo lo que soy

Y no soy tan raro...

Sin embargo, no todos podemos asumir los emblemas de la diferencia con facilidad, ya que el mascultismo se encuentra siempre alerta ante la subversión. El asesinato de Daniel Zamudio evidencia este estado del terror, adiestrando guerrilleros de la hombría y la muerte que patrullan la ciudad de noche.

Esta no es la primera agresión homofóbica que se ha perpetrado en nuestro país. Desde el retorno a la democracia muchos han sido los actos de agresión contra mujeres lésbicas y heterosexuales, gay y travestis y ninguno hasta ahora había tenido tal impacto.

Me sorprende ante todo la reacción del Gobierno, haciendo gala de una apertura disfrazada, ya que por décadas obstaculizó cualquier iniciativa que derivase en la libertad de los cuerpos y del deseo. Cabe recordar que en noviembre del año 2011 fue el bloque de derecha quien negó la aprobación de la Ley antidiscriminación en el Parlamento. 
Pedro Lemebel también manifiesta su desconcierto ante esto:

Este crimen al hacerse mediático, "parece" politizarse al impulsar la ley antidiscriminatoria, pero también la sobre-exposición en la pantalla también tapa todos los crímenes anteriores ocurridos, se necesitaba un mártir joven y bonito para la farándula marica.

Si hubiera sido vieja o trava no sería lo mismo, estas utilizaciones necrófilas son detestables.

Escuchar que esta forma de tortura y masacre es única es desconocer lo ocurrido en dictadura, para tapar la complicidad derechona. (en declaración de Organización Chilena de Estudiantes de Psicología, OCEP)

Ciertamente estos acontecimientos revelan un fenómeno de clase y marginalidad, donde solo aquellos, discretos, hermosos y masculinos gays, defensores de la igualdad, han tenido un espacio en las agendas gubernamentales. Negociando su reconocimiento, y una alianza políticamente correcta, pero que desconoce la libertad de los cuerpos y la sexualidad fuera de los ghetos que el propio heterosexismo ha generado.

En este ámbito concuerdo con las palabras de la columna de The Clinic, en su artículo titulado "El efecto Zamudio", aludiendo al aprovechamiento político que se ha hecho de este asesinato:

Daniel Zamudio tuvo que morir, después de 24 días luchando contra un destino infranqueable, para que reaccionaran las instituciones y autoridades pro vida del país. No bastó el estupor que causaron los detalles de su cobarde golpiza, ni las dos cuadras de velas y cartas afuera de la Posta Central para sacudirse antes. (...) Zamudio tuvo que morir para sacudir a la primera autoridad del país y obligarlo a cachetear públicamente al oficialismo por impedir la aprobación de una Ley Antidiscriminación. (29 de marzo, 2012)

Me extraña que se hable de "igualdad", pero aún se desconozca el derecho de muchos individuos a ejercer su sexualidad libremente, sancionada por Ley en el artículo $N^{\circ} 373$, el cual señala que "los que de cualquier modo ofendieren el pudor o las buenas costumbres con hechos de grave escándalo o trascendencia, no comprendidos expresamente en otros artículos de este Código, sufrirán la pena de 
reclusión menor en sus grados mínimo a medio". Este artículo fue creado el 12 de noviembre de 1874 y ha sido utilizado por los celadores del cuerpo, para evitar prácticas tan ingenuas como un beso o una caricia entre personas del mismo sexo, hasta hechos ridículos como repartir condones en el espacio público como forma de prevención del VIH.

Justamente algunos conservadores han reprobado los hábitos sexuales de Daniel, los espacios que frecuentaba y la cuota de responsabilidad que le cabe en su propia tortura y asesinato. El abogado UDI Jorge Reyes, coordinador de la Red Por la Vida y la Familia, dijo hace algunas semanas en radio Cooperativa: "Al parecer hay una visión romántica respecto de lo que podría ser la tolerancia hacia los homosexuales (...) Creo yo que si la sociedad conociera la realidad de la vida de este niño (...) tendría una opinión distinta".

Pero no ha sido el conocimiento del otro y de sus hábitos lo que ha generado la segregación y el rechazo, sino los propios silencios a los que hemos sido forzados. El caso de la jueza Karen Atala, quien perdió la tuición de sus hijas al hacerse pública su homosexualidad, es emblemático, ya que con ello develó la posibilidad de establecer una nueva ética de las afectividades fuera de la heterosexual. Las agencias de control reaccionaron con rapidez, sometiéndola a sanciones de forma personal y profesional.

Hay algunos, incluso más cínicos, como la filósofa Teresa Marinovic, que sostiene que evitar estas agresiones contra un sector de la población, (que ha sido sistemáticamente ultrajada y torturada) es un privilegio. Desconociendo que el derecho a la vida y la integridad es un derecho fundamental. Y que ha sido la población heterosexista la que ha generado los privilegios al instituir un sistema de sumisión y asimilación.

Es por ello que no podemos circunscribir la muerte de Daniel a un acto delictual común, desligando la responsabilidad que le cabe a un sistema patriarcal de intolerancias sobre la sexualidad, las mujeres, los inmigrantes, indígenas, pobres, etc. Tal como señala Mario Vargas Llosa en un artículo titulado "A la caza del gay", este grupo representa "la avanzadilla más cruda y repelente de una cultura de antigua tradición que presenta al gay y a la lesbiana como enfermos o depravados que deben ser tenidos a una distancia preventiva de los seres normales porque corrompen el cuerpo social sano". 
La tortura aún se practica en nuestro país, como herencia cultural y política institucional. Me refiero a la represión contra los estudiantes, los pobladores en Aysén, inmigrantes y Mapuche. Policías que golpean y violan mujeres, travestis y gay, avalados por un sistema de exclusión.

Por mucho tiempo esto era parte de la normalidad, convencidos que fuera de este margen solo acontecía el caos. Por ello Karen no podía mantener la custodia de sus hijas, ni Daniel caminar sensual por los parques nocturnos de la ciudad. Pero la sociedad civil se ha liberado de los preceptos de control y ya no es posible soportarlo más, lo marginal ha dejado de ser lo oculto. Así lo expresa Juan Manuel Cabrera en su artículo "Los Aplausos que venían desde lejos":

$\mathrm{Al}$ parecer es consenso que no hay espacio para torturar un cuerpo, sin apellidos (pienso en: gay, comunista, delincuente, pobre). Las actuales generaciones que convivimos en Chile tenemos experiencias diversas sobre la tortura y violencia sobre los cuerpos, y tras décadas de historias, ya parece no es algo normal ni aceptable. Se denuncia, se repulsa. El Estado chileno queda en vergüenza frente al mundo, pero principalmente frente a su pueblo.

Los actos de odio y tortura son la base de un sistema del terror, disimulados en los más sutiles discursos de religiosidad, justicia y legalidad. Incubando el germen devorador de la muerte, de la guerra y de la violencia. Cuidemos que no suelten los gendarmes nuevamente a los perros feroces desgarrando los cuerpos, mutilándoles, siendo el arma de aniquilación de un modelo de violencia y orden, de salvajismo y de moral, de normalización y extirpación. ¡Sujetemos a los perros!

En este Dossier hemos presentamos los testimonios de algunas y algunos que han alzado la voz pública y anónimamente contra la violencia de género y la sexualidad. Mediante cartas, poemas, dibujos, oraciones, declaraciones públicas y artículos. Destacan los testimonios y manifestaciones espontáneas, como el dibujo y poema en homenaje a Daniel Zamudio del artista Leonardo Ibañez o la "Carta de disculpas a Daniel" de Antonio Jerez depositada en el frontis de la Posta Central. Además de fotografías de las vigilias en la Posta Central y la Marcha Antidiscriminación. 


\section{Homenaje del artista Leonardo Ibáñez a Daniel Zamudio}

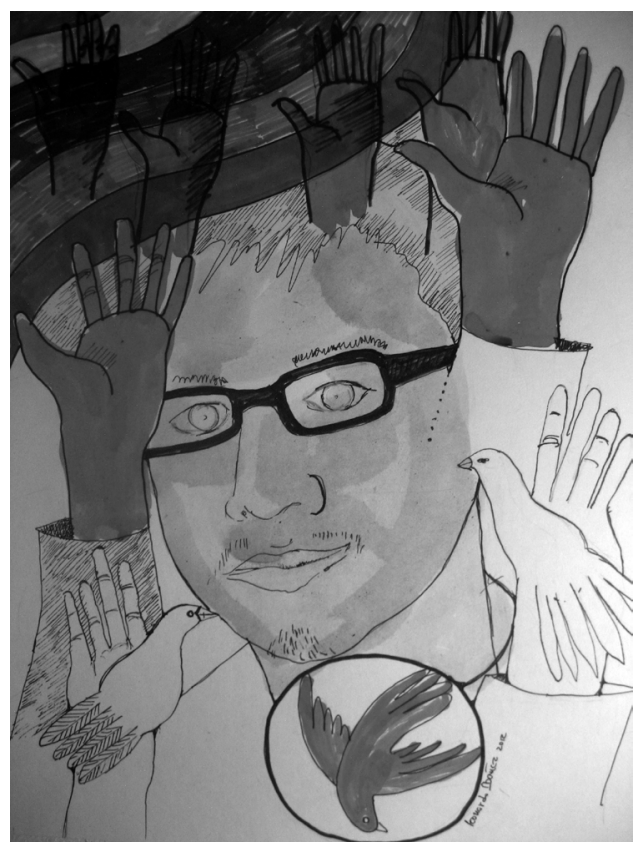

\section{Para Daniel Zamudio}

Daniel, has partido llevando en tú corazón herido sonrisas, lágrimas, esperanzas y nuevas convicciones de una patria estupefacta por el acto bestial que sesgó tus sueños.

Otros, Daniel sufrieron tu misma muerte horrorosa me parece que la pesadilla que envuelve nuestra tierra no se ha disipado, los discípulos de la muerte acechan en cualquier rincón.

Debemos levantar nuestros índices para señalar el espanto de los odios anidados en las miradas de soslayo y los susurros de pasillos.

Las palomas han de anidar en tu nombre para que en sus vuelos lo lleven a los alerces en un solo canto de amor. 


\section{Extractos de "La caza del gay", de Mario Vargas Llosa*}

"El gay es siempre el otro, el que nos niega, asusta y fascina al mismo tiempo, como la mirada de la cobra mortífera al pajarillo inocente".

"vida cotidiana condenada a la inseguridad, al miedo, la conciencia permanente de ser un réprobo, un anormal, un monstruo".

"cuántos jóvenes atormentados por esta censura social de que son víctimas los homosexuales han sido empujados al suicidio o a padecer de traumas que arruinaron sus vidas".

“Liberar a América Latina de

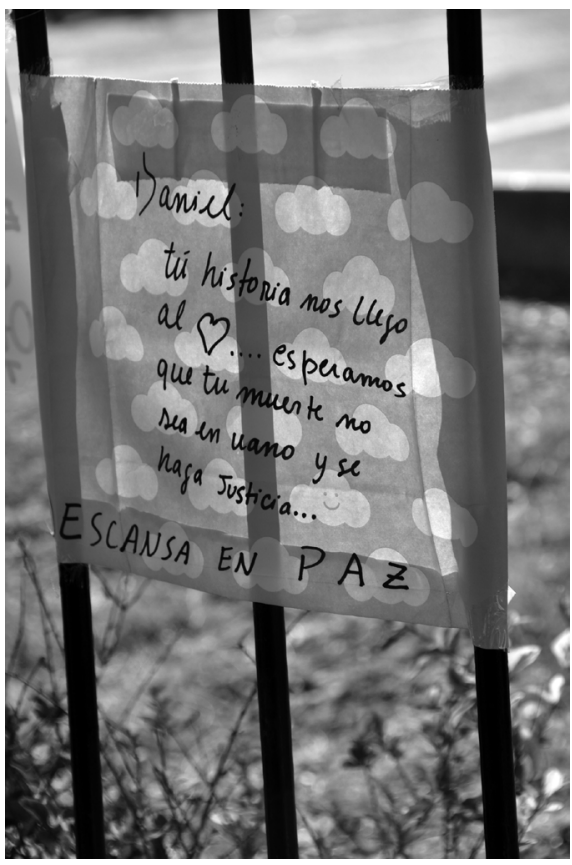
esa tara inveterada que son

el machismo y la homofobia -las 2 caras de una misma monedaserá largo, difícil y probablemente el camino hacia esa liberación quedará regado de muchas otras víctimas semejantes al desdichado Zamudio".

"Ojalá la inmolación de Daniel Zamudio sirva para sacar a la luz pública la trágica condición de los gays, lesbianas y transexuales en los países latinoamericanos, en los que, sin una sola excepción, son objeto de escarnio, represión, marginación, persecución y campañas de descrédito".

* Artículo publicado en la Revista Mexicana Piedra de Toque. 


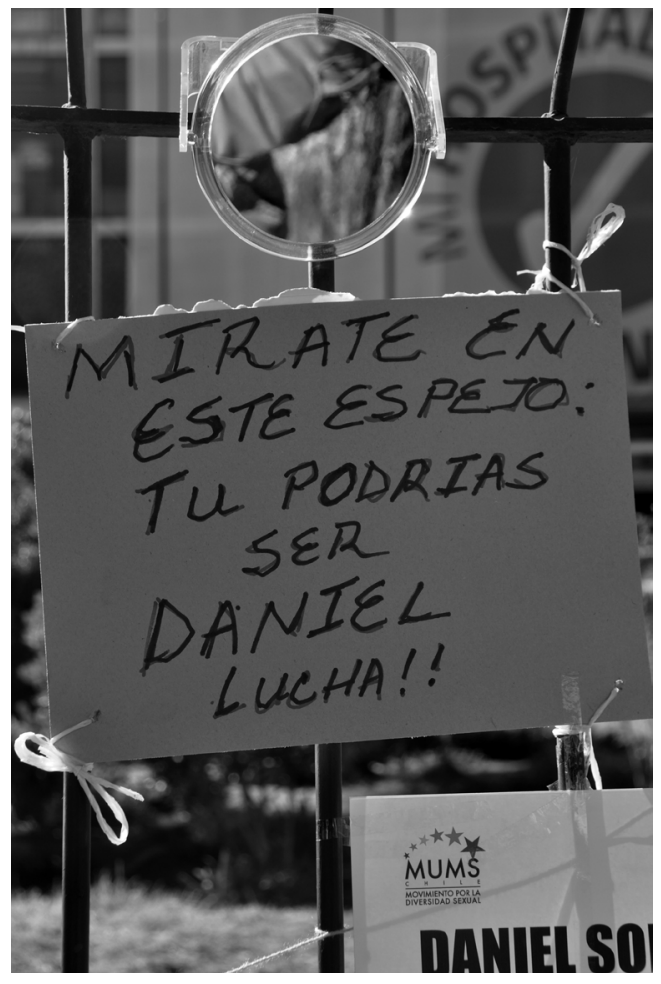

Carta de disculpas por la muerte de Daniel Zamudio del actor Antonio Jerez, dejada en el frontis de la Posta Central entre velas $y$ súplicas*

"Perdón, porque no fuimos capaces de mostrarte otro mundo, perdón por esa oscuridad a la que nuestra indiferencia y falta de interés te ha arrastrado.

Perdón por nuestros niños, porque siguen la senda establecida de la burla. En este mundo de la burla, los gordos, los feos, los fletos, los cojos, los tuertos, las putas, los narigones, las solteronas, los culones, los indios de mierda y los comunistas asquerosos que habitan esta incómoda costumbre chilena de encasillar y despreciar.

Perdón, porque no vivirás para disfrutar de la mano, abrazado a quien hubieses elegido para amar, una tarde de domingo.

Perdón, porque inexplicablemente volveremos a idiotizarnos con el fútbol y la farándula televisiva de turno. Y tu muerte será una cronología más de este Chile de mierda.

Perdón, porque seguiremos nuestra vida a medias, a trancazos, a bofetadas, pero siempre a medias. Y perdón, porque este país que hemos soñado se deshilvana con las ideologías de un Dios sexista, opresor y homofóbico.

Perdón por nuestras leyes obsoletas.

Perdón por nuestros chistes a la diferencia. Por nuestra superficialidad agarrada al consumo diario de tanta televisión.

Perdón por la clase política que tenemos. Una clase política que da vergüenza.

Perdón por tanto perdón, pero es que he intentado entrar en tu socorro profundo y me lo ha impedido la frialdad, el fútbol, los 
realities, la discriminación, la fe idiota, el sermón anticuado, la hostia recocida, el cura y la monja ignorante, el evangélico espumoso de la Plaza de Armas, el centro comercial, mis tarjetas de crédito, mi cuenta bancaria, mi ideología política y corrupta, mi gobierno fascista de turno, las tetas de la mina de la tele, el gol de Alexis Sánchez, el ovni que vio la Maldonado, la teleserie de la noche... Perdón, pero tengo que terminar de algún modo y no sé por dónde.

Perdón, porquehemoscreadounDiosanuestroantojoy conveniencia. Perdón a tu madre por no estar en sus internos desgarrándonos con su dolor".

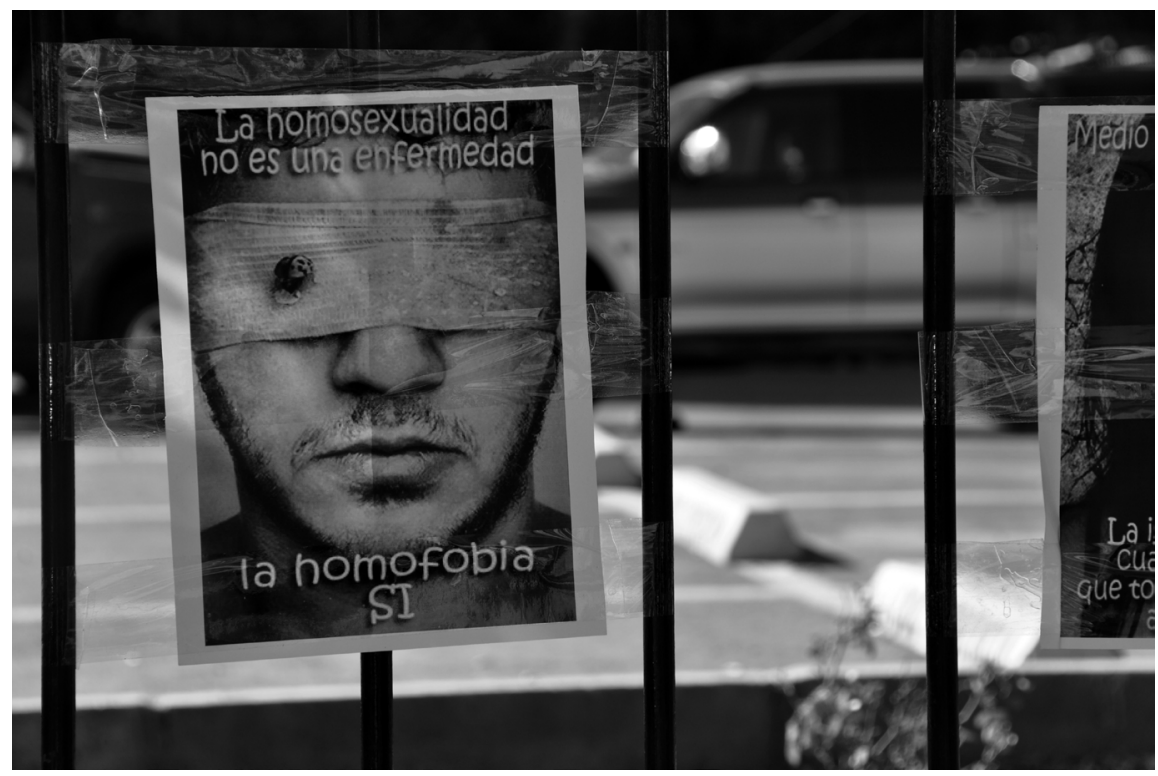

* http: / / www.cooperativa.cl / la-carta-de-disculpas-a-daniel-zamudio-en-laposta-central/prontus_nots/2012-03-28/101708.html 


\section{Extractos de "Los aplausos que venían desde lejos". Juan Manuel Cabrera, grupo de género Julieta Kirwood}

Los aplausos que venían desde lejos anunciaban su llegada. El calor de la ciudad se empecinó. Corrieron periodistas buscando la primicia, con cámaras incómodas, llenando de cables el suelo pisoteado por la masa que repletamos el lugar. Un improvisado escenario albergó palabras políticas de líderes de movimientos; algunos cantos que decían quién dijo que todo está perdido, yo vengo a ofrecer mi corazón; y a una familia que jamás imaginó ese momento, pidiendo respeto y no politizar la despedida de su Daniel Zamudio Vera.

En el Cementerio General éramos miles de personas que acompañamos el entierro de Daniel, luego de agonizar casi un mes tras la tortura que sufrió por una pandilla neonazi. Daniel era hombre, joven, pobre y homosexual. Vivía en San Bernardo, en un pasaje donde apenas pasa el carro de bomberos, donde se pierde la ciudad. En ese pasaje le velaron los y las vecinas, amononaron el lugar sacando sillas de sus casas, poniendo flores, preparando jugo para las visitas.

A medida que ingresaba el auto con el ataúd de Daniel, todo se subyugó al ensordecedor "Daniel, amigo, el pueblo está contigo". Vieja consigna de la nunca acabada injusticia. Las banderas estaban agónicas por la falta de aire, pero coloreaban el cemento del camposanto.

\section{En Chile hay tortura.}

Mujeres son torturadas y asesinadas por razones de género. Se llama femicidio. Al menos en un quinto de los femicidios las mujeres fueron masacradas, desfiguradas, con alevosía, con dolo, con odio. Con moral, la que encarrila, la que designa con sangre la verdad y limpieza.

El asesinato de Daniel es el de un homosexual pobre, la de un gay de pasajes. No debe pasar desapercibido: homosexual + pobre. Y los pobres tienen la justicia del pueblo: de la marcha mientras arriba quema el sol, la del Daniel amigo, el pueblo está contigo, la del show televisivo en los matinales; la de decenas de años siendo marginados, expulsados, explotados. Daniel fue enterrado en un nicho al fondo del Cementerio, cuando ya no hay más donde caminar, donde se capea el sol con malla kiwi, tan alejado de los mausoleos de presidentes, de notables, de burgueses (...) 
En Chile desde todos lados "lamentaron el hecho", como dice la prensa. En verdad, me alegré de no ver curas, ni monjas, ni gente de la política institucional. Despedí, sin conocerlo, a una persona que, sin buscarlo, remecerá necesariamente nuestros límites como sociedad (...)

Sin embargo, la lucha en Chile es ardua. Luchamos desde quienes acaparan todo, hasta quienes no tenemos más poder que un twitter y la esperanza del Kino una vez a la semana.

No me digan que el aborto o interrupción del embarazo es algo valórico; no lo es más que la reforma tributaria o de educación. Es como decir es humano: todo lo es.

No me digan que legislar sobre la discriminación es un avance: es una vergüenza. Es la premodernidad, es el medioevo con Redcompra.

No me hablen de democracia si el debate es sobre la idea de debatir el aborto o interrupción del embarazo, para que luego el Padre Presidente diga que, sin importar lo que se resuelva, vetará la discusión.

No me digan que hablar de femicidio, de aborto, de embarazos, de posnatal, es un tema de mujeres. Menos que es valórico. Decir lo último es caer en la trampa católica de la Santísima Concepción: todo lo que se sea del ombligo para abajo es valórico.

Lo ocurrido con Daniel Zamudio no debiera entenderse como algo aislado, ni como un acto exclusivo contra los/as homosexuales desde un exaltado grupo radical conservador. Lo sucedido es la tortura y asesinato de un miembro de la sociedad que no cumplió mandatos de género y de clase coherentes. Esto ocurre todos los días. Lo de Daniel es el absurdo de lo cotidiano, la vulgarización de una práctica camuflada en nuestras palabras, bromas, publicidad, incluso en campañas gubernamentales que dicen que maricones son los que golpean a determinados grupos.

Cuando ya nos íbamos del Cementerio, recorriendo los pasos hacia Av. Recoleta, comiendo un helado de \$200, una señora de edad algo cansada pero satisfecha, me dijo que el asesinato de Daniel es responsabilidad de todos/as. Lo primero que pensé: fuerte es la asimilación del lenguaje periodístico. Pero luego de unos minutos, comprendí lo básico que la sociología enseña en sus primeras lecciones: el sentido común, esa voz en almacenes y paseos por la calle, 
dice las verdades silenciosas que cimentan nuestras relaciones, resumidas en palabras que escuchamos en todos lados, en cada muro, en muchas canciones. Y la señora me recordó que la comunidad ha fallado, que la polis no existe, que no sabemos de diversidad, que nos tiene aniquilados / as el sentido de la propiedad.

No hay palabra más silenciosa que la del sentido común, y no hay otro lugar en donde escuchar más fuerte el estruendo de la vida social (...)

Vendrán los discursos, mejor que vengan libertades. Vendrán los gestos, mejor que vengan las acciones. Vendrán las promesas, mejor que vengan resoluciones. Vendrán más torturas y discriminaciones, y ahí mejor que sea el sentido común quien aplaste esa violencia; entonces, la ley o reforma que sea, será solo un dato de la causa. Nuestra mejor arma es que sea anormal lo sucedido con Daniel, siendo él un símbolo de discriminados/as, abusados/as y explotados / as. Nunca un mártir.
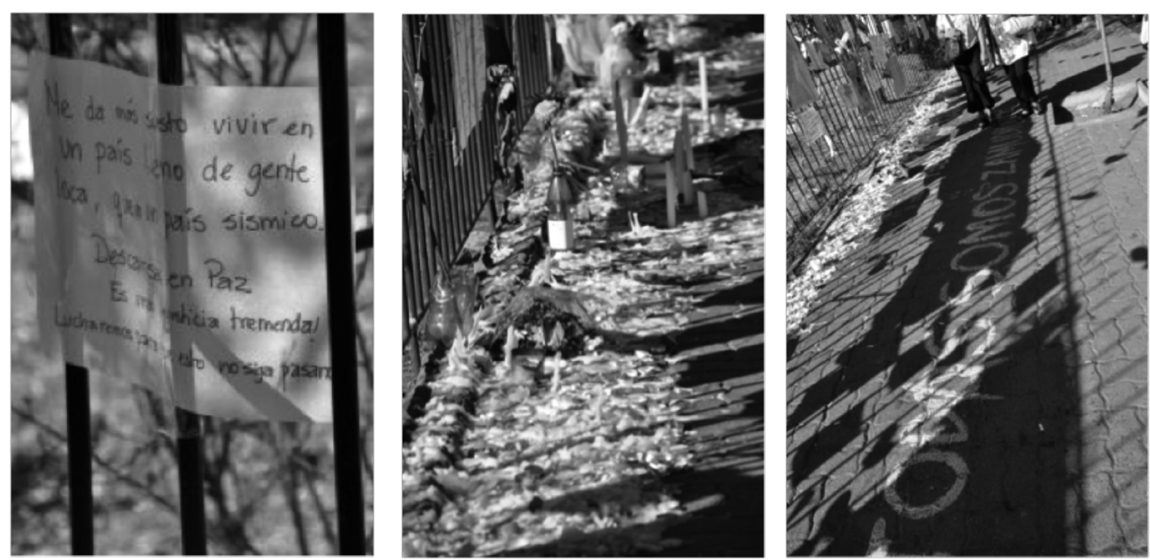


\section{Manifiesto (Hablo por mi diferencia) Pedro Lemebel}

No soy Pasolini pidiendo explicaciones

No soy Ginsberg expulsado de Cuba

No soy un marica disfrazado de poeta

No necesito disfraz

Aquí está mi cara

Hablo por mi diferencia

Defiendo lo que soy

Y no soy tan raro

Me apesta la injusticia

Y sospecho de esta cueca democrática

Pero no me hable del proletariado

Porque ser pobre y maricón es peor

Hay que ser ácido para soportarlo

Es darle un rodeo a los machitos de la esquina

Es un padre que te odia

Porque al hijo se le dobla la patita

Es tener una madre de manos tajeadas por el cloro

Envejecidas de limpieza

Acunándote de enfermo

Por malas costumbres

Por mala suerte

Como la dictadura

Peor que la dictadura

Porque la dictadura pasa

$\mathrm{Y}$ viene la democracia

$Y$ detrasito el socialismo

¿Y entonces?

¿Qué harán con nosotros compañero?

¿Nos amarrarán de las trenzas en fardos

con destino a un sidario cubano?

Nos meterán en algún tren de ninguna parte

Como en el barco del general Ibáñez

Donde aprendimos a nadar

Pero ninguno llegó a la costa

Por eso Valparaíso apagó sus luces rojas

Por eso las casas de caramba 
Le brindaron una lágrima negra A los colizas comidos por las jaibas

Ese año que la Comisión de Derechos Humanos no recuerda

Por eso compañero le pregunto ¿Existe aún el tren siberiano de la propaganda reaccionaria? Ese tren que pasa por sus pupilas Cuando mi voz se pone demasiado dulce ¿Y usted?

¿Qué hará con ese recuerdo de niños Pajeándonos y otras cosas En las vacaciones de Cartagena ¿El futuro será en blanco y negro? ¿El tiempo en noche y día laboral sin ambigüedades?

¿No habrá un maricón en alguna esquina desequilibrando el futuro de su hombre nuevo? ¿Van a dejarnos bordar de pájaros

las banderas de la patria libre?

El fusil se lo dejo a usted

Que tiene la sangre fría

$Y$ no es miedo

El miedo se me fue pasando

De atajar cuchillos

En los sótanos sexuales donde anduve

Y no se sienta agredido

Si le hablo de estas cosas

$Y$ le miro el bulto

No soy hipócrita

¿Acaso las tetas de una mujer

no lo hacen bajar la vista?

¿No cree usted que solos en la sierra

algo se nos iba a ocurrir?

Aunque después me odie

Por corromper su moral revolucionaria

¿Tiene miedo que se homosexualice la vida?

Y no hablo de meterlo y sacarlo 
Y sacarlo y meterlo solamente

Hablo de ternura compañero

Usted no sabe

Cómo cuesta encontrar el amor

En estas condiciones

Usted no sabe

Qué es cargar con esta lepra

La gente guarda las distancias

La gente comprende y dice:

Es marica pero escribe bien

Es marica pero es buen amigo

Súper-buena-onda

Yo no soy buena onda

Yo acepto al mundo

Sin pedirle esa buena onda

Pero igual se ríen

Tengo cicatrices de risas en la espalda

Usted cree que pienso con el poto

Y que al primer parrillazo de la $\mathrm{CNI}$

Lo iba a soltar todo

No sabe que la hombría

Nunca la aprendí en los cuarteles

Mi hombría me la enseñó la noche

Detrás de un poste

Esa hombría de la que usted se jacta

Se la metieron en el regimiento

Un milico asesino

De esos que aún están en el poder

Mi hombría no la recibí del partido

Porque me rechazaron con risitas

Muchas veces

Mi hombría la aprendí participando

En la dura de esos años

$Y$ se rieron de mi voz amariconada

Gritando: Y va a caer, y va a caer

$Y$ aunque usted grita como hombre

No ha conseguido que se vaya

Mi hombría fue la mordaza 
No fue ir al estadio

Y agarrarme a combos por el Colo Colo

El fútbol es otra homosexualidad tapada

Como el box, la política y el vino

Mi hombría fue morderme las burlas

Comer rabia para no matar a todo el mundo

Mi hombría es aceptarme diferente

Ser cobarde es mucho más duro

Yo no pongo la otra mejilla

Pongo el culo compañero

Y ésa es mi venganza

Mi hombría espera paciente

Que los machos se hagan viejos

Porque a esta altura del partido

La izquierda tranza su culo lacio

En el parlamento

Mi hombría fue difícil

Por eso a este tren no me subo

Sin saber dónde va

Yo no voy a cambiar por el marxismo

Que me rechazó tantas veces

No necesito cambiar

Soy más subversivo que usted

No voy a cambiar solamente

Porque los pobres y los ricos

A otro perro con ese hueso

Tampoco porque el capitalismo es injusto

En Nueva York los maricas se besan en la calle

Pero esa parte se la dejo a usted

Que tanto le interesa

Que la revolución no se pudra del todo

A usted le doy este mensaje

Y no es por mí

Yo estoy viejo

Y su utopía es para las generaciones futuras

Hay tantos niños que van a nacer

Con una alita rota

Y yo quiero que vuelen compañero 
Que su revolución

Les dé un pedazo de cielo rojo

Para que puedan volar
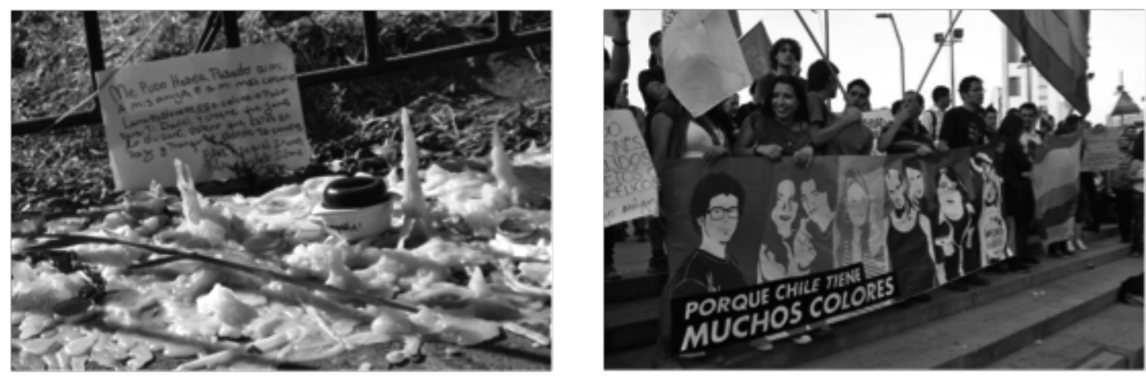

Extracto Declaración Pública de la Organización Chilena de estudiantes de Psicología (OCEP): “A todos ellos/as: ¡Daniel Zamudio Presente!"

Daniel Zamudio no puede ser un número más en la estadística, no permitamos que la violencia se apodere de nuestros espacios de formación, pues la psicología tiene y debe existir en función de los pueblos y comunidades, y no en función de la dominación y la explotación, sea cual sea su expresión; basta de permitir que los psicólogos y las psicólogas nos transformemos en gendarmes de la subjetividad, en policías mentales, en cómplices de los verdugos.

Daniel, aunque nunca te conocimos, mientras estés en nuestra memoria seguirás vivo en el corazón de los que luchamos contra toda discriminación e injusticia.

OCEP, jueves 29 de marzo 

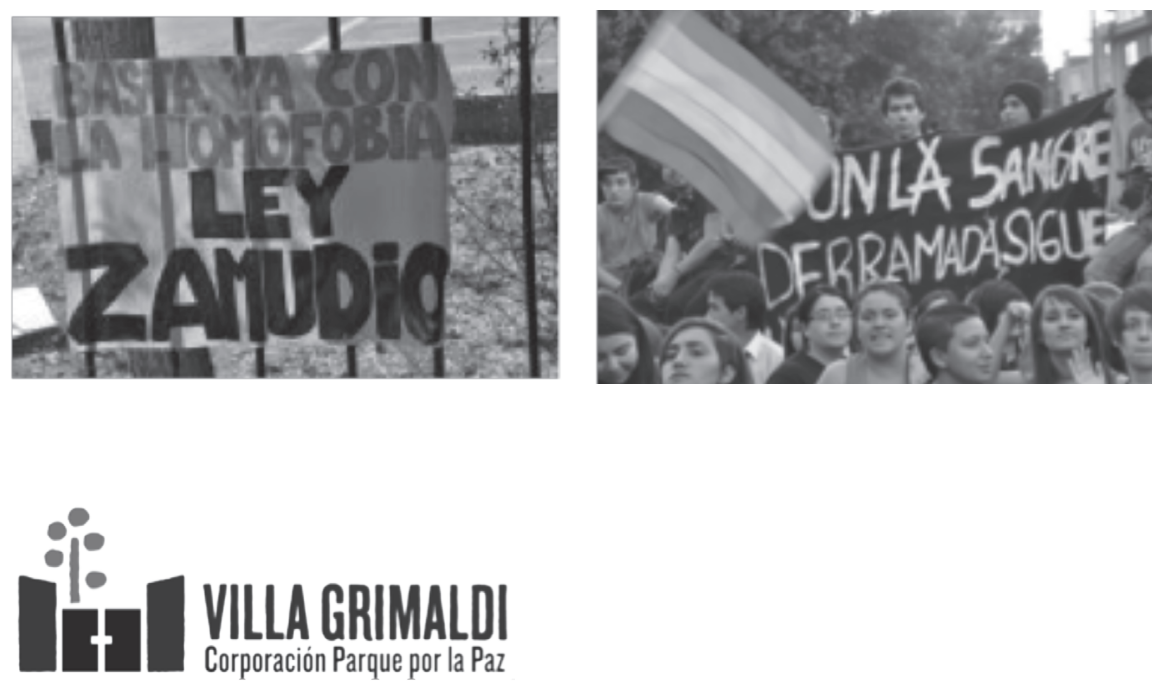

\section{Declaración Parque por la Paz Villa Grimaldi}

La agresión y posterior muerte del joven Daniel Zamudio, es un termómetro del Chile real, porque refleja dramáticamente niveles de intolerancia, xenofobia y persecución a personas por ser distintas. En este caso, a un joven que asumía su homosexualidad. En otros, ha sido la condición de ser emigrante peruano, mapuche, viejo, pobre, minusválido o el pertenecer a alguna tribu urbana, entre muchas posibilidades.

En las calles de Chile aún es peligroso ser distinta o distinto.

La muerte de Daniel Zamudio, más allá de sus ejecutores materiales, tiene su origen en el déficit existente en educación de derechos humanos en todos los niveles; en el predominio sexista y patriarcal de muchos contenidos en los medios masivos y muy particularmente en los canales de la televisión abierta. También en la segmentación de los barrios y las comunas de nuestras ciudades.

No se trata solo de la muerte de Daniel Zamudio, sino de múltiples evidencias. Los femicidios que al repetirse, pareciera nos acostumbran a su ocurrencia. También, se extiende al fallo adverso de la Corte Interamericana en contra del Estado chileno por el caso de la jueza Atala; las denuncias de un condominio de Huechuraba que impide circular a ciertas horas y por ciertos lugares a sus trabajadores y trabajadoras de servicios; las detenciones por sospechas y 
el maltrato de carabineros a jóvenes; el comportamiento de la policía frente a niños y mujeres mapuche o hacia vecinos en Aysén. En suma, la irracional violencia que le cuesta la vida a Daniel Zamudio no es un hecho aislado en nuestra sociedad.

En definitiva, es la ausencia de una democracia con plena vigencia de derechos ciudadanos, donde los ciudadanos y ciudadanas deben respetarse entre si y a la vez ser respetados por los agentes del Estado, cualquiera sea su opción sexual, política, religioso, lugar de origen o condición social, el desafío aún pendiente.

A nuestra Corporación Parque por la Paz Villa Grimaldi, la muerte de Daniel Zamudio la interpela y hace rememorar...

La violencia que ayer secuestró, torturó e hizo desaparecer o ejecutó en falsos enfrentamientos a miles de compatriotas y que hizo de la violencia sobre cuerpos inermes y reducidos una forma de castigo y control social.

Chile no solo necesita leyes que protejan la diferencia. Por sobretodo necesita más y mejor educación, que tenga como eje el respeto al otro distinto y practique la tolerancia. Necesitamos educación y barrios integrados, donde la heterogeneidad se enseñoree y vuelvan a primar los espacios públicos.

Al padre, madre y hermanos de Daniel Zamudio, a sus amistades y vecinos toda nuestra fraternidad en esta hora.

Peñalolén, 29 de marzo 2012

\section{Declaración Pública de Karen Atala}

Fui y soy madre por opción, sin embargo se me negó el derecho a criar a mis propias hijas por un prejuicio y la existencia de un estereotipo negativo sobre las personas de orientaciones sexuales diversas.

Hoy recibo tranquila este fallo de la Corte Interamericana de Derechos Humanos, que viene a restablecer el imperio de la justicia para mí y mi familia, revirtiendo la jurisprudencia que por años me privó de la tuición de mis hijas. Lo recibo con la certeza de que ha quedado claro que las familias son diversas en su composición e iguales en dignidad. Vivir de acuerdo a la identidad sexual de cada persona 
no será, como nunca debió ser, unimpedimento para ejercer una maternidad y paternidad afectuosa, responsable, acogedora y cariñosa.

Tengo una profunda esperanza de que con esta condena internacional al Estado de Chile se dignifique a todas aquellas madres y padres que han visto restringidos sus derechos por su orientación sexual.

Agradezco profundamente a mi equipo de abogados y abogadas, de Libertades Públicas AG, Corporación Humanas y Centro de Derechos Humanos de la Universidad Diego Portales, quienes durante estos casi 9 años, entregaron todo su profesionalismo y pasión por hacer de éste un país más justo y respetuoso de los derechos humanos. Agradezco, también, a mi familia, amigas y amigos, los que han estado a mi lado en cada momento de este largo proceso.
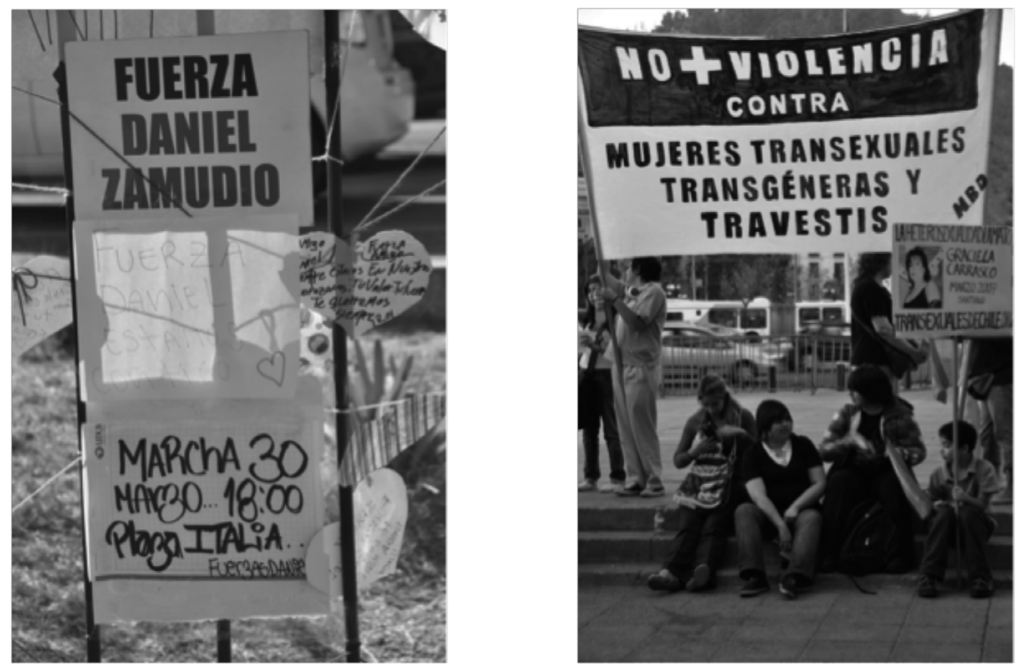

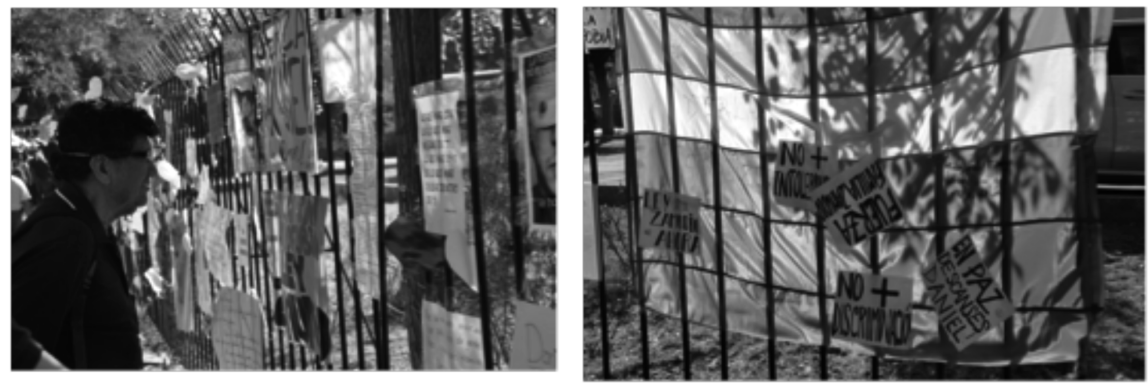

Para representar el dolor hay que emancipar la lágrima. Sobre performance SU-MISIÓN de Felipe Rivas San Martín

Es lo que trato de decir, que hay que interrumpir la lógica del discurso amoroso. Quizás es ese el único objetivo de un proyecto de izquierda.

(Miguel Valderrama)

Jorge Díaz F.?

La pregunta por cómo representar el dolor de aquellos que han sufrido las consecuencias de habitar los bordes de la actual política de la identidad, aquella que ve en sus individuos blancos, heterosexuales y burgueses su mayor éxito reproductivo, ha quedado muchas veces reducida a una suerte de melancolía que aloja tímidamente su horror, en las estrategias del respeto y la compasión por los cuerpos maltratados.

En Chile, el mediatizado crimen del joven homosexual Daniel Zamudio en manos de autodenominados "neonazis", promovió una importante agitación social que cambió la agenda de quienes aún ven en la asimétrica relación con el Estado, una posible solución legislativa a la actual precariedad de nuestros cuerpos e identidades. 
Donde antes decía "matrimonio homosexual" ahora dice "no discriminación".

La política así entendida sería entonces un espacio donde solo está en disputa la posibilidad de ser -ya sea vivo o muerto- visto. De ahí entonces la importancia de representaciones que cuestionen ese lugar donde opera el ojo de la política, para reacomodar con relaciones de fuerza la ecología visible de sus ciudadanos.

De esta manera, Felipe Rivas San Martín interrumpió en el imaginario sentimentalizado de la muerte de Daniel Zamudio con su performance "SU-MISIÓN". En la acción, -teniendo como audio de fondo el tema "Toxic" de la cantante pop Britney Spears reproducido en loop- se utilizó principalmente dos espacios como territorios a intervenir: por un lado una superficie de papel blanco donde trazó una esvástica con vino tinto de la marca "Exportación" que expulsaba a sorbos por su boca y, por otro lado su propio torso donde marcó nuevamente la esvástica con un bisturí. Leyó el prólogo del libro Mi lucha de Adolf Hitler, mientras efectuaba el cepillado de sus dientes, haciendo la lectura casi ininteligible hasta llegar a provocarse arcadas y finalizó su acción levantando un cartel con la frase "EN EL ARTE DE PERFORMANCE LA SANGRE ESTÁ PASADA DE MODA". El signo de la esvástica aparece doblemente inscrito: tanto en el perímetro que enmarca la acción (su base), como el cuerpo del artista (su torso), de la misma manera como los asesinos de Zamudio lo hicieron en su cuerpo con una botella rota. Dos son territorios que se inscriben problemáticamente en el título de la acción desde espacios aparentemente desconectados: la predestinación y el autosometimiento.

El discurso que sustenta las lógicas cristianas de la vocación habla siempre desde la voz de la predestinación: existe una misión previa a la existencia del cuerpo que debería cada ser humano supuestamente realizar como motivo de un supuesto plan ya trazado de antemano (SU-MISIÓN). De esta forma, Felipe Rivas cuestiona esa supuesta misión de Zamudio evocada en el discurso que acompañó su agonía y muerte ${ }^{8}$ pero no como sacrificio sino como autosumisión escogida. Una autosumisión que se hace parte de aquel dolor que frecuentemente se tiende a rechazar como marca de una violencia que se inscribe en aquellos cuerpos vistos como menos útiles y que la política rechaza en la representación de ellos mismos. Pero, le- 
yendo esta performance debemos dudar de esos discursos y estéticas que ven en sí mismos una identidad sin daño, puesto que tienden a formar un cuerpo siempre victorioso y congruente que no ahonda en las contradicciones sociales y culturales que existen en su misma construcción.

Si como dice el filósofo Jacques Rancière "las prácticas artísticas son 'maneras de hacer' que intervienen en la distribución general de las maneras de hacer y en sus relaciones con maneras de ser y formas de visibilidad"9 esta performance de Felipe Rivas pretende exponer sin discreción, las estrategias que conforman los ordenamientos estéticos que catalogan a algunos como oprimidos bajo un signo ordenado y claro, dudando de ciertas estructuras de la violencia que, en la figuración humanista de la lágrima, crean una totalidad donde es imposible intervenir.

A su vez, la performance -en el cartel levantado al final- nos habla de cierta incomodidad ante la pérdida del compromiso del arte con la misma pregunta por la representación de aquellos que están "fuera de lugar". De esta manera, la acción se hace extraña de ella misma y se desvincula de cierto circuito que adosa su trabajo al éxito pasajero de la moda tomando la muerte de Daniel Zamudio como espacio biográfico a intervenir.

Así, pareciera que adentrarse en los territorios de la representación de la violencia tiene una importante necesidad ya no sólo para denunciar sino más bien para encarnar y emancipar eso que denominamos como "la sensibilidad". Y de ahí la importancia de esta acción, pues logra desvincular-sin melancolía—esa constitución sensible en la que nuestros cuerpos minoritarios parecieran estar siempre presos. 
Performance Felipe Rivas ${ }^{10}$

Pienso en los marcos de violencia. En que a la violencia que te puede matar, le sigue una segunda violencia de victimización social. Y que ambas, tanto la violencia física como la violencia que te construye como víctima sólo pueden ser resistidas desde otra violencia (estética, política, de protesta).

(Felipe Rivas San Martín)

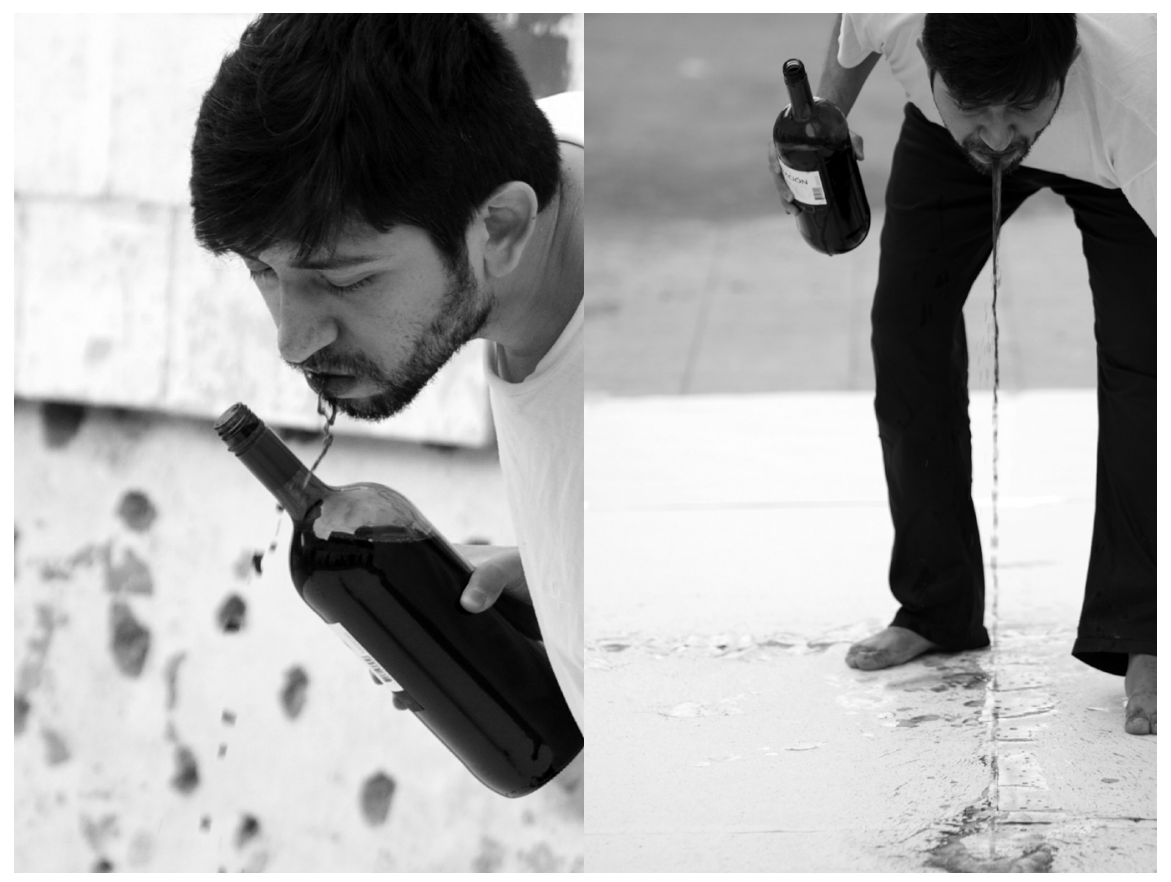




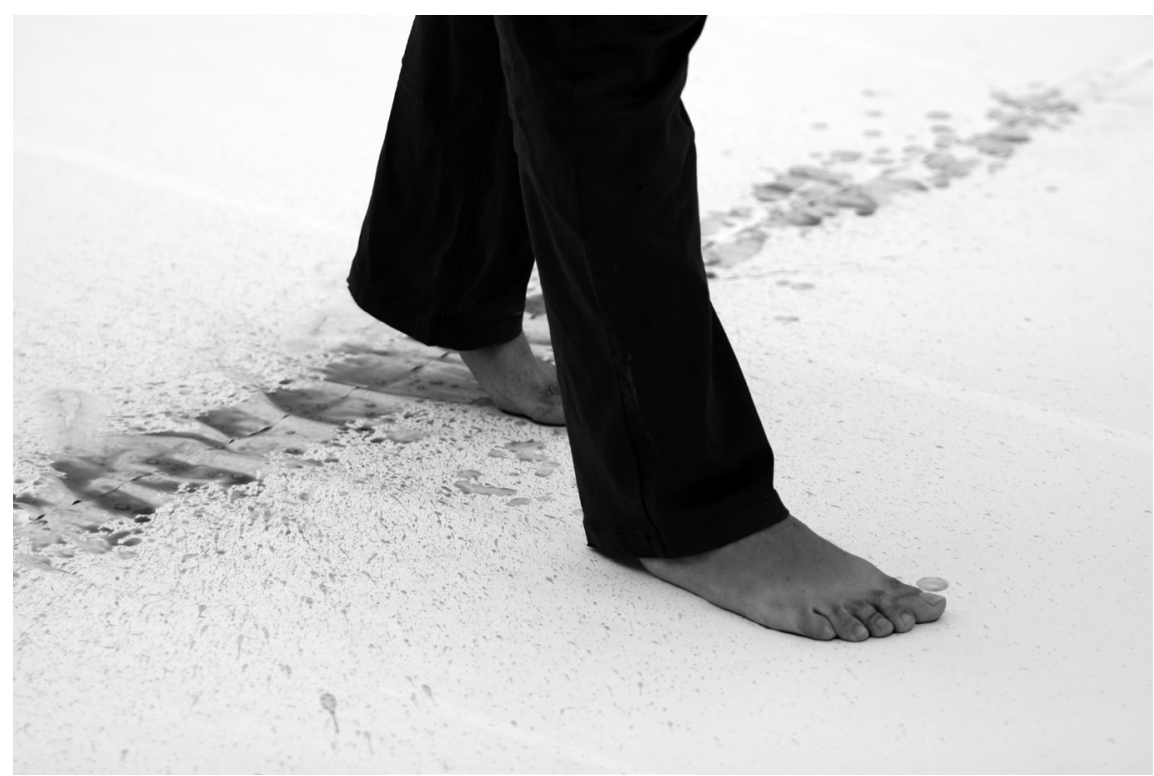

\section{Notas}

1 Didier Eribon. Reflexiones sobre la Cuestión Gay. Barcelona: Anagrama, 2001.

2 David Halperin. San Foucault. Para una hagiografía gay. Buenos Aires: Ediciones literales, 2007.

3 En 2005 el presidente del MUMS -Gonzalo Cid- fue detenido por distribuir condones en un parque de ligue gay, en el marco de una campaña de pretensión del sida, bajo la figura legal de "ofensas al pudor, la moral y las buenas costumbres".

4 http:/ / www.emol.com/noticias / nacional/2012/04/09/534803/jorge-reyessobre-ley-antidiscriminacion-es-una-parafernalia-politica.html

5 Teresa Marincovic. “Usted Paga el Precio de la Ley Antidiscriminación”. El Mostrador.cl http://www.elmostrador.cl/opinion/2012/04/11/\%C2\%BFustedpaga-el-precio-de-la-ley-antidiscriminacion/

6 Este texto fue leído como intervención en un acto político de la izquierda en septiembre de 1986, en Santiago de Chile.

7 Estudiante de Doctorado en Bioquímica de la Universidad de Chile y activista de la disidencia sexual. Trabaja con CUDS (Coordinadora Universitaria por la Disidencia Sexual) un grupo de práctica performática y política que interrumpe en el imaginario tradicional de la izquierda, el feminismo, la escritura teórica y el análisis estético.

8 En el discurso fúnebre de Daniel Zamudio, el Movimiento de Integración y Liberación Homosexual MOVILH dijo “Daniel se fue cuando pensó que su 
trabajo aquí ya estaba hecho, cuando tuvo la certeza de que había llegado a cada corazón y que había aportado más, mucho más que un grano de arena. Había nacido para algo grande" disponible en: http: / / www.movilh.cl/index. php?option=com_content\&task=view\&id=1316\&Itemid $=1$

9 Jacques Rancière. El reparto de lo sensible. Santiago: Editorial Lom, 2009, 10-11.

10 Duración aproximada de la acción: 15 min. Fotografías de Fabián Andrés Camberoy Alejandro Rogazy. 